\title{
Observation of temperature and velocity in the coastal water off Kuala Terengganu, Malaysia
}

\begin{abstract}
Mooring observation of current and temperature was made at $17.8 \mathrm{~m}$ layer of $19 \mathrm{~m}$ depth about $8 \mathrm{~km}$ east to Kuala Terengganu, Peninsular Malaysia. Harmonic analysis was applied to tidal currents for 30 days in September 1993, and to the tides observed at Chendering. The $\mathrm{K} 1$ tide was the largest both in tidal currents and the tides. Daily mean temperature, currents, sea level, and winds were analyzed from September 1993 to May 1994. Northeast Monsoon from December to February caused sea level rise of $50 \mathrm{~cm}$ and temperature lowering of $1{ }^{\circ} \mathrm{C}$.
\end{abstract}

Keyword: Mooring observation; Kuala Terengganu; Temperature; Velocity 